\title{
The Inheritance and Educational Significance of Huaxian Shadow Play in Kindergarten Games
}

\author{
Sihong Zhao
}

\author{
School of Preschool Education, Xi'an University, Xi'an, China 710065
}

Keywords: Huaxian Shadow; Kindergarten; Game; Heritage

\begin{abstract}
Traditional culture is the inner spiritual foundation of a nation's existence and development. The relationship between traditional culture and education is inseparable. Education that is separated from the traditional culture is just a simple inheritance of knowledge. Traditional culture without educational communication lost the environment for survival and development. With the economic and social development, people's pursuit of the spiritual level is moving towards a higher and broader level. The traditional culture is profound and has a long history. In the new historical period, how to fully tap the value of education in traditional culture is not only a social problem, but also an educational issue. Shadow Play of Huaxian is a bright pearl of art in traditional Chinese culture. Huaxian Shadow Play is applied to education, which has very important social functions and educational potentials.
\end{abstract}

\section{Introduction}

Traditional culture is an important resource of a country. Traditional culture is an organic component and an important external manifestation of national spirit, national emotion, national history, national temperament and national cohesion. Any country attaches great importance to the protection and inheritance of its own traditional culture, especially for the developed countries. With the development of economy and society, the standard of living of our people has been steadily moving forward. While pursuing the quality of material life, the pursuit of spiritual life has also reached a higher level. In recent years, great efforts have been made in the protection of traditional culture from state to the relevant scholars. The most effective way to protect the traditional culture is to let the traditional culture fully enter into the learning of students and enter the common life. In the author's opinion, we still have a long way to explore in terms of how to protect our traditional culture. Traditional culture should not only be a symbol or a history, but should exist in our lives and exist in people's words and actions. The sooner and the better students can get in touch with the traditional culture, the more they have a tremendous impact on their future formation of personal cultural quality. The culture formed in the childhood can support and promote one's life.

\section{Current Situation of Huaxian Shadow}

The World Heritage Assembly, held in Mexico in 1982, for the first time raised the concept of intangible cultural heritage and the 2003 UNESCO Convention for the Safeguarding of the Intangible Cultural Heritage was adopted at its 32nd session. At this point, the protection of traditional culture has formed a worldwide norms. However, the world's intangible cultural heritage is only a small part of the traditional culture of all countries. Our country has a long history and numerous traditional cultures, which have more universality and urgency for the protection of various traditional cultures.

Shadow of Huaxian is a classic representative of China's outstanding traditional folk culture, which is also known as shadow play and it is a unique form of folk art. Although there are more types of shadow play, Huaxian Shadow is recognized as one of the masters by both domestic and overseas shadow play. Huaxian Shadow is best qualified to represent the highest standards of Chinese and foreign shadow art, and even some scholars call it the father of Chinese drama. According to historical research, shadow play in Huaxian began in the Han Dynasty of Chang'an 
more than 1500 years ago. There is a shadow on the record In the "Han Book". Historian Gu Jie Gang think that the origin of China Shadow is Shaanxi Huaxian after careful study. In 2006, Huaxian Shadow Project was selected as China's first national intangible cultural heritage. In 2011, Huaxian Shadow Project was also included in the list of United Nations humanity's intangible cultural heritage as a part of China's shadow. Shadow Play has been loved by the majority of the people from the birth to thousands of years of development. With the development of society, the civilization of the industrial revolution dyed the style of the traditional farming civilization. Under the constant impact of the brand-new audiovisual methods such as the network, television and mobile phones, the traditional art form became unsustainable. Up to now, the majority of Huaxian shadow play has been lost and most of the artists have also quit the show under the pressure of life. According to the survey data, there are currently only about 15 performing artists in Huaxian shadow play. Among them, the elderly over sixty occupy eight. With the continuing downturn in the performance market, the lives of the majority of these artists are unsustainable.

\section{The Contemporary Education Value of Huaxian Shadow Play}

Before talking about the contemporary educational value of China Shadow, we should first understand the many qualities of Huaxian Shadow play. Huaxian Shadow has a long history, which is very well-produced and delicately carved. It is a brilliant work in Chinese shadow art. Compared with other shadows, the most prominent feature of the Huaxian Shadow is that its shape is based on characters. The shape of the shadow figure is small and smart with detailed attire and patterns, making it a very strong sense of three-dimensionality. The material of Huaxian shadow generally uses high-quality leather, exquisite carving and character modeling lifelike, which make each shadow a work of art. The shadow play artists have profound vocals and choose bowl bowl cavities. All the Sheng, Dan, Jing, and Chou is sang by one person. A shadow theater is generally composed of five people. In addition to singing and dialogue, there are more than 20 musical instruments such as tiaoxian, erhu and banhu. Each of whom has basically assumed more than four roles. There is also an artistic feature that distinguishes Huaxian Shadow Play from other shadow arts. That is, the tiaoxian of Huaxian Shadow Play is performed by one person.

Because the Huaxian Shadow has these artistic qualities, the author thinks that it has a very wide range of promotion and application value in the field of education from the beginning of the contact, especially for early childhood education. First of all, Huaxian shadow playable. The Huaxian Shadow Play only need a simple venue and a limited number of performances. Most kindergartens have such conditions. Second, Huaxian shadow figure is lifelike and performance is very contagious. Toddlers can not comprehend and generate interest in complex scene changes and long stories. However, Huaxian shadow can show the evolvement of the story with vivid characters and body movements, and it is very easy to stimulate young children's learning interest. For simple shadow shows, children can also be grouped to complete. Shadow performance requires performance team set shadow manipulation, music accompaniment, folk art singing in one, many people collaborative. Such a teamwork is conducive to cultivating children's sense of responsibility and solidarity, conducive to shaping children's non-utilitarian aesthetic value and aesthetic personality and conducive to cultivating children's dedication and control of emotions. Throughout the shadow play operation, the children's intelligence, practical ability, coordination and control have been fully trained and coordinated development. The shadow play activities not only strengthen the child's subjectivity, but also cultivate their collective spirit. Finally, there are more art categories covered by shadow art, which is a comprehensive art form. The introduction of shadow art into early childhood education will greatly enrich the content of early childhood education. The drawing, carving, and coloring in the process of making shadow arts can enrich the children's art curriculum. Besides, shadow play and dance can strengthen children's perception of music. Simple shadow-making has great value in exercising children's logical thinking and ability to practice. The logic of the production process can effectively stimulate the child's left brain potential, letting children unconsciously enrich their thinking ability and enhance their intelligence level. 


\section{The Application of Huaxian Shadow in Kindergarten Games}

Shadow play mainly starts as a kindergarten game. The following steps should be main planned and controlled in the game design and implementation.

Watching Is the Premise for the Start of the Game. Due to the special age, children's learning of things generally starts from imitation, so the contact with the shadow play should start from the viewing. "San Da Bai Gujing", "Zhu Bajie eat watermelon" and other shadow play content is vivid and easy to understand, so these classic shadow play can deeply attract children's curiosity and mimicry. Teachers can give children a brief introduction of shadow play and tell them that shadow play is an art form invented by our ancestors very early on so that children can have a general impression of shadow play at a macroscopic level. With the progress of the shadow play, children will be attracted to this special art form. At this time, teachers should give a little guide and children's enthusiasm for participation will be very high.

The Content of Shadow Play Should be Close to Children's Features. The shadow play that children watch should not be too complicated. Whether in the design of the scene or the plot of the story, or the design of characters should be fully considered. Performance figures and performance content should be designed from the perspective of children. Besides, the shadow play content can also be modelled on games or movies that children are familiar with and try to keep close to child's life. Moreover, teachers can also adapt the classic children's literary works into a shadow play, exploring the shadow play forms on the basis of preserving the shadow art style and making breakthroughs.

Try to Let Children Decorate the Shadow Corner of the Classroom. Teachers can also combine school education with home education, and give children a certain amount of extra-curricular interest in homework to let children spend more time out of class with their parents and look for their favorite shadow works, stamps, postcards and even advertisements. The shadow submitted by children can be assigned by themselves to arrange the shadow corner belonging to the class.

Keep Children Close to the Shadow Production. With these foreshadowing before, teachers can let children visit the process of making shadow puppets and let them feel the process of the birth of shadow puppets. Apart from the visits, children can also make some simple shadow shapes by themselves. In classroom teaching, teachers can use some lighter and softer materials instead of the actual material of the shadows to allow children to make shadow figures. In the production, teachers can help children build a wealth of knowledge and experience in the interactive cooperation based on the principle of nurturing and enlightening, but also prepare for young children into more outstanding folk culture.

\section{The Promotion of the Shadow Education Value in Huaxian}

Cultural heritage is an important way for human civilization to continue. Inherit and develop Huaxian Shadow Play which is a traditional folk culture is not only our contemporary responsibility, but also has far-reaching significance. The development of the educational value of Huaxian Shadow is still at the preliminary stage of exploration. With regard to the current achievements and experiences, the author believes that the promotion of the educational value of Huaxian Shadow Play should focus on the following aspects.

Make Great Efforts to Explore the Fusion of Shadow Art and Modern Education. As an ancient art form, shadow art has great educational potential. How to integrate this ancient art form into modern education is a new topic that every educator should value and explore. This not only provides a possibility for the rejuvenation of the shadow arts, but also expands the vast space for modern education, which is a process of mutual promotion. Everyone must also remember Tan Weiwei's "Huain Laoqiang Shout". This song organically combines the old thick and modern elements of Huayin's old voice. Once it was launched, it achieved great success and aroused strong social repercussions. In this song, you can't tell the old and the modern and it instantly brings the glory of ancient artistic achievements. Never underestimate the power of traditional culture. 
Try to Integrate Traditional Cultural Elements into Textbooks. Looking at our education, it can be found that one of the obvious problems is that students' textbooks are not enough for the implantation of traditional cultural factors. The traditional culture of our country is a splendid treasure that has been precipitated during the long process of development. It has nourished generation after generation of Chinese descendants and has also impelled the formation of the national spirit. Textbooks, as an important means of teaching and cultural heritage, should include more national factors, allowing students to continuously experience the wisdom and history of our nation at all stages of learning and give children more influence in the aspect of cultural literacy.

Research the Combination of Production and Learning of Shadow. Enhance the modernization of shadow show performance with the combination of production and learning of shadow to let more people have more access to this art form. The current inheritance and development of shadow mainly follows the ancient method and there is no regularity for reference. We should make more effort to research the combination of production and learning of shadow. Relying on the scientific advantages of specific organizations, we can make the shadow arts more widely available and the viewing channels more convenient.

\section{Conclusion}

For a nation, the exhaustion of the spiritual world means the collapse of the national form. Any art form is the accumulation of one nation and one nation's humanities and history. Therefore, to protect the traditional culture is to protect the nation itself. The promotion and deepening of Huaxian Shadow in the field of education is not only the need of traditional culture but also the need of deepening the content of education and advocating quality education. We must combine our traditional culture with education in a deep-rooted way with a sense of responsibility, so that the traditional culture will have a better development in modern education.

\section{Fund Project}

The 13th Five-Year Plan Education Science in Shaanxi Province 2017 Program: On the Application and Inheritence of Shadow Play of Huaxian County in Kindergarten Games (Project No. SGH17H235)

\section{Reference}

[1] Y. M. Chen. Chinese Folk Art, Miscellaneous Notes, Puppet Shows, Shadow Play [M]. Beijing: Culture and Arts Press, 1998, p. 167; p. 74.

[2] G. G. Xu. Huaxian Shadow [J]. Folk Culture Youth Forum, July 2, 2003.

[3] X. Yu. Drama in Shaanxi Province. Xi'an: Sanqin Press, 1996 edition, p. 75.

[4] Z. P. Huang. 20th Century Chinese Film and TV Studies Centennial Review [J]. Guangxi Education, 2006 (23).

[5] J. S. Chen. Drama and Entertainment [M]. Shanghai: Shanghai People's Press, 2003,7.

[6] X. B. Tang. Dilemma and Outlet of Folk Opera under the Dual Pressure of Art Treasures [J]. Beijing Youth Daily, September 1997.

[7] G. T. Li. Drama Crisis and Outlet [J]. Literary Newspaper, 1986.

[8] S. L. Zhao. Yunnan Ethnic Culture Heritage Outline [M]. Kunming: Yunnan Nationalities Press, 2002, 17.

[9] Y. Sha. Shadow of Huaxian. Record of "Jianghuren" [N]. People's Daily: Overseas Edition, 2008-12-09.

[10]K. H. Zhao and J. Z. Qi. New Bright Spot of Millennium Ancient Shadow [N]. China Quality News, 2009-10-29. 